\title{
Grafit Cevherleșmelerinin Sentinel-2 Uydu Görüntülerinden Belirlenmesinde En Uygun Bant Kombinasyonları
}

\author{
Muhittin Karaman ${ }^{1 *}$ \\ 1* İstanbul Teknik Üniversitesi, Maden Fakültesi, Jeoloji Mühendisliği Bölümü, İstanbul, Türkiye, (ORCID: 0000-0002-8971-010X), mkaraman@ittu.edu.tr
} (İlk Geliş Tarihi 31 Mayıs 2021 ve Kabul Tarihi 15 Ağustos 2021)

(DOI: 10.31590 /ejosat.945779)

\begin{abstract}
ATIF/REFERENCE: Karaman M. (2021). Grafit Cevherleşmelerinin Sentinel-2 Uydu Görüntülerinden Belirlenmesinde En Uygun Bant Kombinasyonları. Avrupa Bilim ve Teknoloji Dergisi, (25), 749-757.

$\ddot{O ̈ z}$

İleri teknoloji potansiyeli yüksek ülkelerin bu hedeflerini gerçekleştirmesi doğrultusunda birçok uluslararası organizasyon tarafından grafit minerali, kritik hammadde olarak tanımlanmıştır. Grafit yatakları, grafitin yüksek ısı ve elektrik iletkenliği, yüksek 1sıya dayanıklılığı gibi özellikleri nedeni ile ileri teknoloji konularında kullanımı ve önemi yaygınlaşan stratejik bir cevherleşmedir. Gelecekte özellikle Grafen kullanımının giderek artacak olması nedeniyle, amorf grafit yatakları bakımından zengin olan ülkemizdeki yeni grafit maden yataklarının ülke ekonomisine kazandırılmasında uzaktan algılama yöntemlerinin kullanımının değerlendirilmesi bu çalışmaya konu edilmiştir. Bu bağlamda bu yatak oluşumları için Sentinel-2 uydu görüntülerinde kullanılabilecek en uygun spektral bant kombinasyonları, optimum indeks faktörü ile belirlenmiş ve başarımları değerlendirilmiştir. Atmosferik düzeltme için geliştirilen bantlar değerlendirme dışı bırakılmıştır. Grafit yataklarının, su, bitki, kömür ocakları ve diğer litolojik birimlerden başarılı bir şekilde ayrımlanabilmesini sağlayan optimum FCC (False Color Composite) renkli görüntü, [RGB 4:7:11] ve [RGB 4:8:11] kombinasyonuna aittir. Sentinel-2 uydu görüntüleri grafit yataklarının belirlenmesinde, algılayıcısının spektral aralığı ile grafitin karakteristik spektral özelliklerini barındırmakta ve başarılı sonuçlar üretmektedir.
\end{abstract}

Anahtar Kelimeler: Grafit Cevherleşmeleri, Sentinel-2, Uzaktan Algılama, Optimum İndeks Faktörü (OIF).

\section{Optimal Band Combinations for Determining Graphite Mineralizations from Sentinel-2 Satellite Images}

\begin{abstract}
Graphite raw material has been defined as a critical raw material by many international organizations in order for countries with high technology potential to achieve these goals. Graphite deposits are a strategic mineralization whose use and importance in advanced technology issues are becoming widespread due to the properties of graphite such as high thermal and electrical conductivity and high temperature resistance. The evaluation of the use of remote sensing methods in bringing new graphite mineral deposits in our country, which is rich in amorphous graphite deposits, to the country's economy, is the subject of this study, especially since the use of graphene will increase gradually in the future. In this context, the most suitable spectral band combinations that can be used in Sentinel-2 satellite images for these bed formations were determined by the optimum index factor and their performances were evaluated. Bands developed for atmospheric correction are excluded from the evaluation. The optimum FCC (False Color Composite) color image that enables the successful separation of graphite deposits from water, plants, coal mines and other lithological units belongs to the [RGB 4: 7: 11] and [RGB 4: 8: 11] combination. Sentinel-2 satellite images contain the characteristic spectral properties of graphite with the spectral range of its detector and produce successful results in the determination of graphite deposits.
\end{abstract}

Keywords: Graphite mineralization, Sentinel-2, Remote-Sensing, Optimum Index Factor (OIF).

*Sorumlu Yazar: mkaraman@itu.edu.tr 


\section{Giriş}

Grafit, Avrupa Birliği "Kritik Hammaddeler" listesinde yer alır (Çuhadaroğlu ve Kara, 2018; ENTR, 2014). Mükemmel ıs1 iletkenliği, mükemmel elektrik iletkenliği ve yüksek ısıya dayanıklılığı nedeni ile stratejik bir hammaddedir (Çuhadaroğlu ve Kara, 2018; Demirtaş vd., 2017; ENTR, 2014). Elektrikli araçlardaki artış, buna bağlı olarak lityum-iyon bataryalarda anot olarak grafitin kullanılması nedeni ile son zamanlarda grafite ilgi oldukça artmıştır (Çuhadaroğlu ve Kara, 2018).

Grafit, çelikten 300 kat daha sağlam, en güçlü ısı iletkeni ve en hafif ince madde olmanın yanında kolayca esneyebilme özelliği ile birçok malzeme yüzeyine çok kolay kaplanabilen, geleceğin süper molekülü grafenin, ana kaynaklarından biridir (Çuhadaroğlu ve Kara, 2018). Özellikle elektrikli araç teknolojileri, kurşungeçirmez çelik yelek üretimi, uçak ve otomobil sanayiine kadar her alanda grafen kullanımının yaygınlaşacak olması (Çuhadaroğlu ve Kara, 2018), grafit yataklarını ve bu yatakların aranması ve ekonomiye kazandırılmasını önemli hale getirmektedir.

Pil anotları gibi yüksek teknoloji uygulamaları, elektrikli araç, portatif elektronik cihaz ve büyük ölçekli enerji depolama alanına artan gereksinimler nedeniyle ülkemizin önemli grafit ithalatçısı olduğu (İlhan, Sarı ve Çörtenlioğlu, 2020) göz önüne alındığında bu yatakların ortaya çıkarılması daha da önemli hale gelmektedir. Yeni maden yataklarının ortaya çıkarılması ve grafitteki saflaştırmanın arttırılması amacıyla gerekli yöntemlerin geliştirilmesi, sanayi ve ileri teknoloji potansiyeli olan ülkeler için oldukça kritik bir konudur (İlhan, Sarı, ve Çörtenlioğlu, 2020; İhan, Sar1, ve Y1ldırım, 2020; Jara vd., 2019).

Bu çalışmada önemli bir amorf grafit kaynağı olan ülkemizde yeni yatakların belirlenmesinde uzaktan algılama yöntemleri ve uydu görüntülerinin kullanımının değerlendirilmesi amaçlanmıştır. Özellikle maden uygulamalarında son dönemlerde kullanımı yaygınlaşmaya başlayan Avrupa Uzay Ajansı Sentinel2 uydu görüntülerinin grafit yatağının belirlenmesinde kullanılabilirliği incelenmiştir.

Sentiel-2 uydu görüntüleri Nadir Toprak Elementi aramalarında (Purwadi vd., 2020), demir cevherleşmelerinin aranmasinda (Ge vd., 2020; Soydan vd., 2021; van der Werff ve van der Meer, 2015), hidrotermal alterasyon minerallerinin haritalanmasında (Hu vd., 2018), lityum pegmatitlerin araştırılmasında (Cardoso-Fernandes vd., 2018) kullanılmaktadır. Uydu görüntüleri kullanılarak uzaktan algılama yöntemleri ile maden alanlarının aranmasında bant oranlama, renkli görüntü bileşenleri, temel bileşen analizi gibi görüntüdeki bantların spektral kontrastını vurgulayan görüntü işleme teknikleri yaygın olarak kullanılmaktadır (Ciampalini vd., 2013; Canbaz vd., 2017; Baran, 2021).

Grafitin artan önemi ile birlikte, uzaktan algılama ile doğrudan grafit cevherleşmelerinin belirlenmesi güncel bir konudur. Sunulan çalışmada Sentinel-2 uydu görüntülerinden grafit yataklarının belirlenmesinde kullanılabilecek optimum bant kombinasyonlarının belirlenmesi hedeflenmiş ve Sentinel-2 görüntülerinin bu tür yataklar için kullanımı incelenmiştir. İstatistiksel bir yöntem yaklaşımı ile Sentinel-2 görüntülerinin istatistiksel parametreleri kullanılarak Optimum İndeks Faktörü ile en uygun bant kombinasyonu seçenekleri belirlenmiştir.

\section{Materyal ve Metot}

\subsection{Grafit Madenleri ve Endüstriyel Kullanımı}

Amorf (mikrokristalin), Pul ve Damar olmak üzere doğada üç farklı formu olan Grafit siyah ve gri renkli, sertliği 1 ve yoğunluğu 2'dir (Çuhadaroğlu ve Kara, 2018; MTA, 2021). Rejiyonal metamorfizma alanlarında yüksek tenör ve rezervle sahip olabilen Grafit, metamorfik zonlarda şist ve mermerlerle birlikte bulunur (MTA, 2021). Yüksek dereceli amfibolitik metamorfik kayaçlar, granit, masifler ve yüksek termal gradyan oluşturan ana tektonik bölgelere yakın bölgelerde grafit oluşumları gözlenmektedir (İlhan, Sarı ve Çörtenlioğlu, 2020). Menderes Masifi, Istıranca Masifi, Akdağmadeni Masifi, Sultandağ Masifi (Konya) ve Doğu Bitlis Masifi Türkiye'deki bilinen grafit yataklarının bulunduğu birimlerdir (İlhan, Sarı ve Çörtenlioğlu, 2020; İlhan, Sarı ve Yıldırım, 2020) (Şekil 1). Balıkesir-Susurluk, Kastamonu, Bingöl-Genç, Adıyaman-Sincik, Muğla-Milas-Yayladere, Kütahya-Oysu, İnebolu-Anday, Kahramanmaraş-Göksun, Konya, Yozgat-Akdağmadeni, İzmirTire-Karamersin, Tire-Çeşme, Tire-Başköy ve Kırklareli yatakları Türkiye'deki keşfedilmiş yataklardır (Çuhadaroğlu ve Kara, 2018; İlhan, Sarı ve Çörtenlioğlu, 2020; İlhan, Sarı ve Yıldırım, 2020; Toprak, 2017). Türkiye'deki grafit oluşumları amorf tipindedir (Çuhadaroğlu ve Kara, 2018). Grafitleşme değeri ve tenörü açısından Yozgat-Akdağmadeni Türkiye'nin en iyi oluşumlarındandır.

Grafitlerin saflıklarına ve karbon içeriklerine göre kullanım alanları değişir (Çuhadaroğlu ve Kara, 2018; Demirtaş vd., 2017; İlhan, Sarı, ve Çörtenlioğlu, 2020). Saflığı yüksek olan grafitler, elektrik bataryaları, kuru piller, çelik sanayi ve elektrometalürji sanayiinde, kalem yapımında, elektrik cihazlarındaki elektrotlarda ve reaktörlerde kullanılır (Çuhadaroğlu ve Kara, 2018; Demirtaş vd., 2017; İlhan, Sarı, ve Çörtenlioğlu, 2020). Buna karşın saflığı düşük ve karbon içeriği düşük olan grafit ise refrakter kaplama, dökümcülük, boya sanayii, gres yağlarında kullanılır (Çuhadaroğlu ve Kara, 2018; Demirtaş vd., 2017; İlhan, Sarı, ve Çörtenlioğlu, 2020; İlhan, Sarı, ve Yıldırım, 2020; Toprak, 2017). Ayrıca lastik, araba balataları, motor yağlarında katkı malzemesi olarak kullanılırken, yüksek ateş ve asite dayanıklılığı nedeni ile pota ve laboratuvar malzemelerinin yapımında da kullanılır (Çuhadaroğlu ve Kara, 2018; İlhan, Sarı ve Çörtenlioğlu, 2020).

\section{2. Çalışma Alanı: Kütahya-Oysu Grafit Cevherleşmesi}

Çalışma alanı Türkiye'nin 1990'lı yıllarda başlayan ve aktif olarak işletilen grafit madeninin yer aldığı Kütahya-Oysu yatağıdır (Şekil 2). Özellikle 2004 yılından itibaren grafit talebinin artmasına bağlı olarak yeniden üretimin devam ettiği bölgede (İlhan, Sarı, ve Çörtenlioğlu, 2020), grafit mineralizasyonu Üst Paleozoik yaşlı Emirgazi Formasyonu içinde gelişmiştir (Tufan ve Batar, 2015). Bu birimde grafit oluşumu, amfibolit gnays, şist, kuvarsit ve mermer ile birlikte bulunur (Tufan ve Batar, 2015). Cevher kalınlığının 5-10m arasında değiştiği birimde, cevher zonları tektonizmanın etkisiyle yüksek deformasyon geçirmiştir (Tufan ve Batar, 2015). Eski bir kömür seviyesinin kristalin bir seri içinde bu serinin metamorfizması sonunda oluşan Oysu Grafit cevherleşmesi, mikro kristalin ve makro kristalin grafit türündedir (Karabacak, 2021). Cevherleşmenin metamorfik tabakalar boyunca yayıldığı yatak (Tufan ve Batar, 2015), 7.2 milyon ton grafit cevheri içerirken yatağın potansiyeli 125 milyon tondur (İlhan, Sarı, ve 
Çörtenlioğlu, 2020; Karabacak, 2021). Flotasyon yöntemi ile amorf grafit üretiminin gerçekleştiği yatakta aynı zamanda Antimuan ve Kaolen cevherleşmeleri de bulunmaktadır (Karabacak, 2021).

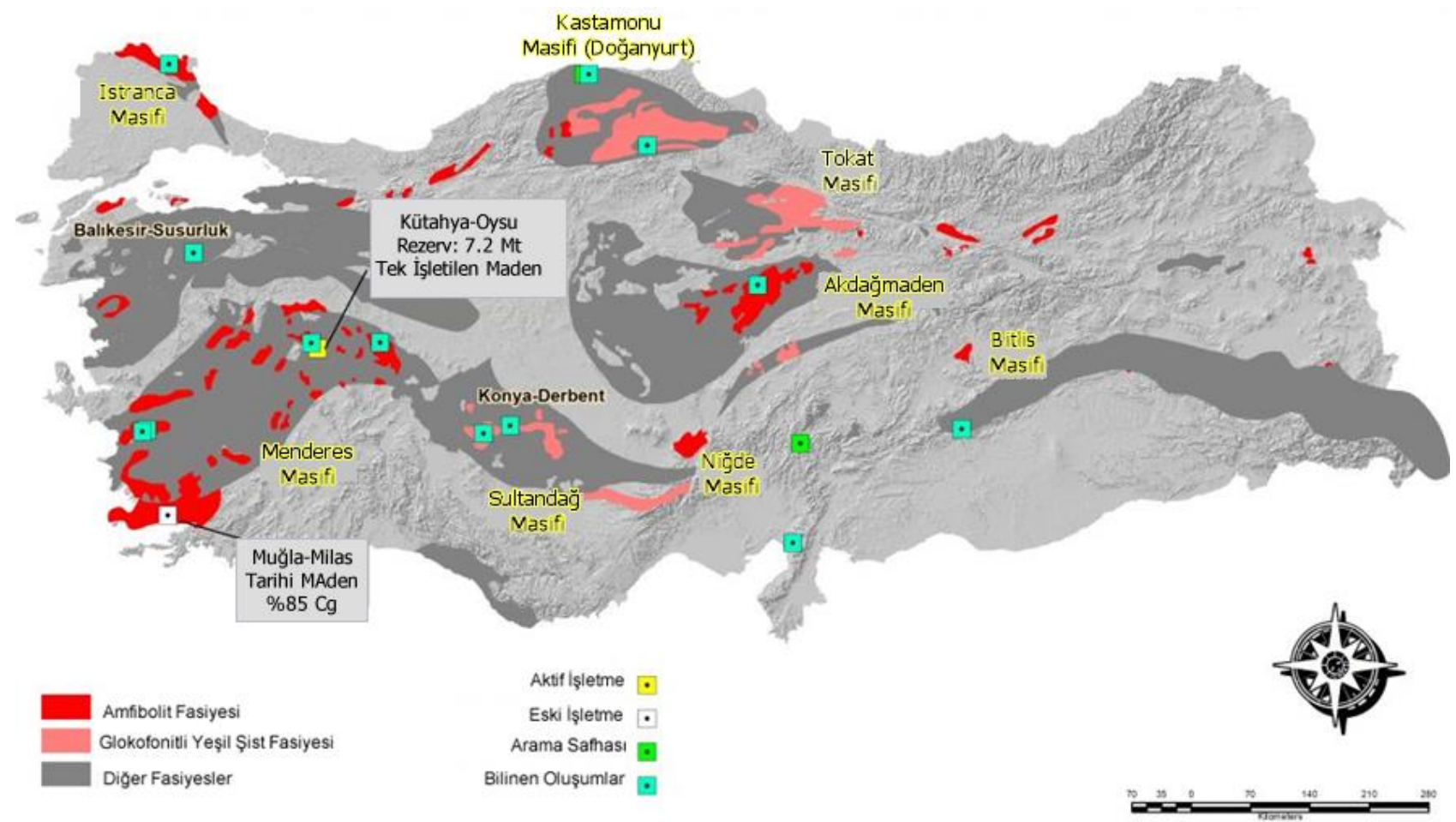

Şekil 1 Türkiye'de grafit oluşumlarl, yatakları ve metamorfik kayaçlar ile litolojik ilişkileri (İlhan, Sarı ve Çörtenlioğlu, 2020)
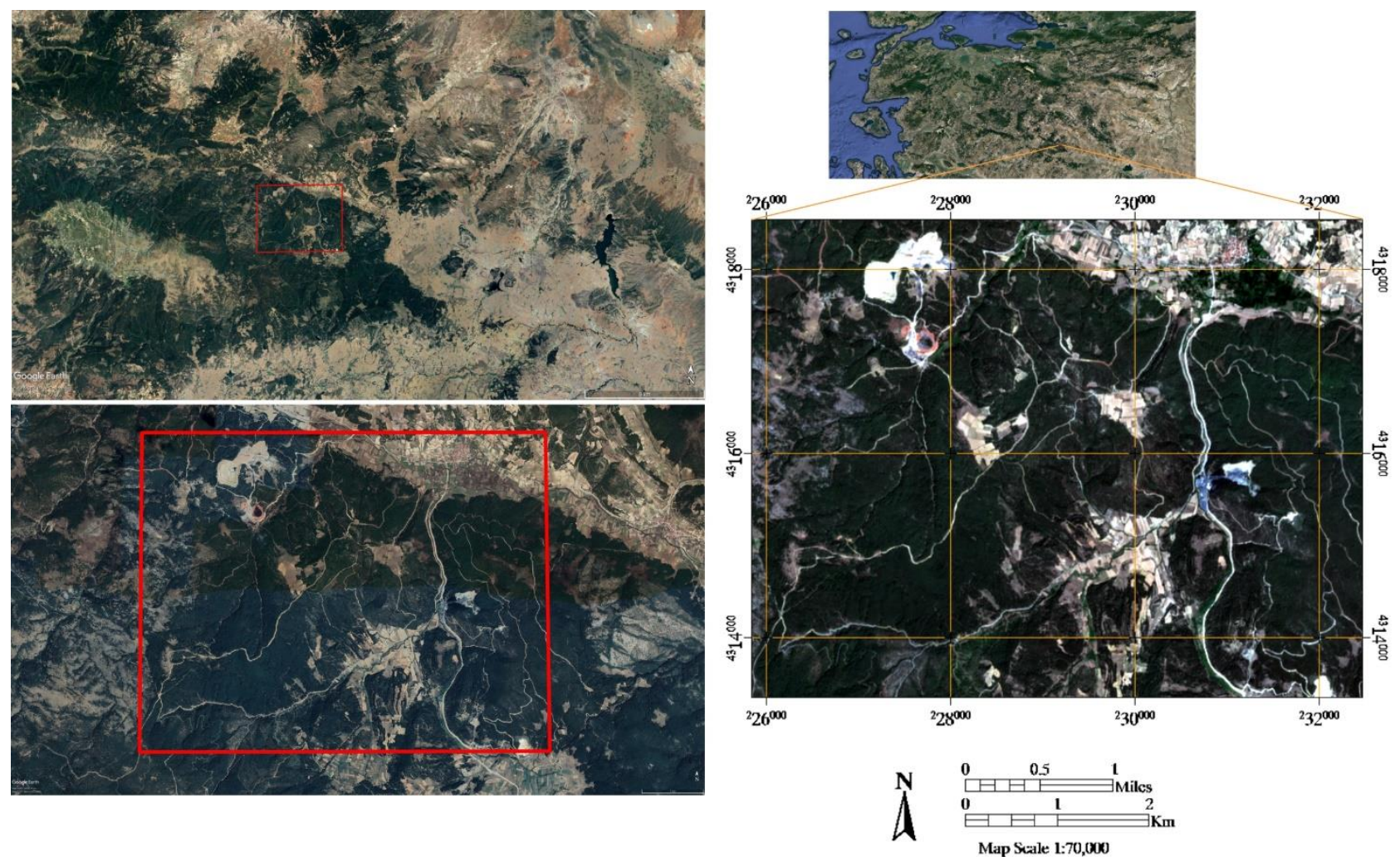

Şekil 2 Çalışma Alanının Google Earth üzerinde görünümü 


\subsection{Sentinel-2 Uydu Görüntüsü}

Grafit maden alanının uydu görüntüleri ve uzaktan algılama yöntemleri ile belirlenmesine ilişkin değerlendirmede Avrupa Uzay Ajansı (European Space Agency: ESA) tarafından ücretsiz olarak sağlanan Sentinel-2 uydu görüntüsünün ikinci seviyede işlenmiş (Level-2A) görüntüsü Copernicus Open Access Hub sistemi üzerinden (https://scihub.copernicus.eu) temin edilmiştir. Sentinel-2 uydu görüntüleri uzamsal çözünürlükleri 10, 20 ve 60 m olarak değişen spektrumun görünür yakın kızılötesi (Visible and Near InfraRed: VNIR) bölgesinde 10 bant ve Kısadalga Kızılötesi (ShortWave InfraRed: SWIR) bölgesinde 3 bant içerir (Tablo 1). ESA Sentinel-2 Level-2 görüntüleri, sistemsel olarak geometrik ve atmosferik düzeltmeleri, ortorektifikasyonu yapılmış görüntülerdir. Sentinel-2 Level-2 görüntülerindeki piksel değerleri aynı zamanda Atmosfer Altı Yansıma değerlerine (Bottom-of-atmosphere (BOA) reflectance) sahiptir. Sentinel-2 Level-2 görüntüleri atmosfer üstü radyans değerlerine (Top-OfAtmosphere (TOA)) sahip 1. Seviye (Level-1C) ortorektifiye görüntülerden Sen2Cor algoritması ile üretilmektedir (ESA, 2013; MuellerWilm, 2019).

Tablo 1 Sentinel-2 Uydu Görüntüsünün spektral ve uzamsal özellikleri (ESA, 2013)

\begin{tabular}{|c|c|c|c|}
\hline Bant & $\begin{array}{l}\text { Merkezi Dalga } \\
\text { Boyu (nm) }\end{array}$ & $\begin{array}{l}\text { Bant Genişliği } \\
\text { (nm) }\end{array}$ & $\begin{array}{l}\text { Uzamsal } \\
\text { Çözünürlük (m) }\end{array}$ \\
\hline 1 & 443 & 20 & 60 \\
\hline 2 & 490 & 65 & 10 \\
\hline 3 & 560 & 35 & 10 \\
\hline 4 & 665 & 30 & 10 \\
\hline 5 & 705 & 15 & 20 \\
\hline 6 & 740 & 15 & 20 \\
\hline 7 & 783 & 20 & 20 \\
\hline 8 & 842 & 115 & 10 \\
\hline $8 \mathrm{~A}$ & 865 & 20 & 20 \\
\hline 9 & 945 & 20 & 60 \\
\hline 10 & 1375 & 30 & 60 \\
\hline 11 & 1610 & 90 & 20 \\
\hline 12 & 2190 & 180 & 20 \\
\hline
\end{tabular}

\subsection{Görüntü İşleme}

Değerlendirmelerde Sentinel-2 uydu görüntüsü bantlarından 60 m uzamsal çözünürlüklü 443 nm'deki 1. Bant, 945 nm'deki 9. Bant ve $1375 \mathrm{~nm}$ 'deki 10. Bant, atmosferik parametrelerin çıkarımı ve atmosferik düzeltme için tasarlandığından (ESA, 2013) bu çalışmadaki değerlendirmelerde kullanılmamıştır. Geriye kalan farklı uzamsal çözünürlükteki 10 Bant, en yakın komşuluk algoritması (nearest neighbor) ile 10 metreye yeniden örneklenerek tüm bantlarda aynı uzamsal çözünürlük elde edilmiştir. $290 \mathrm{~km}$ çerçeve genişliğine sahip uydu görüntüsü çalışma alanını kapsayacak şekilde kesilerek $81 \mathrm{~km}$ x $44 \mathrm{~km}$ genişliğinde çalışma alanına ait alt çerçeve elde edilmiş ve değerlendirmelerde kullanılmıştır. Sentinel-2 uydu görüntülerinin sayısal görüntü işlemleri ESA tarafindan geliştirilen SNAP ver.8.0.3 yazılım aracı ile gerçekleştirilmiştir. Kullanılan görüntülerin projeksiyon ve datumu sırasiyla UTM (Zon 35) ve WGS84'tür.

\subsection{Referans Harita}

Grafit maden sahasına ait açık işletme sınırlarının çıkarımı ve yapılan analizlerin doğruluğunun değerlendirilmesi amacıyla kullanılacak referans veri üretiminde Google Earth üzerinden
Maxar Teknoloji şirketi (http://www.maxar.com) tarafindan sağlanan ve Sentinel-2 uydu görüntüsüne yakın tarihli, 30 Ağustos 2019 tarihli yüksek uzamsal çözünürlüklü uydu görüntüsü kullanılmıştır. Yüksek uzamsal çözünürlüklü görüntüden grafit cevherleşme zonu, açık maden ocağı işletme sınırları, stok saha sınırları gibi tüm bileşenler kolayca ayrımlanabilmektedir (Şekil 3).

\subsection{Optimum İndex Faktör (OIF)}

Optimum indeks faktörü istatistiksel bir değerdir (Chavez vd., 1982). Uydu görüntülerinde normal doğal renkli görüntü (True Color) farklı normal olmayan yalancı renkli görüntü (sahte renk-false color) oluşturmak amacıyla kullanılabilecek optimum 3 bant bileşeninin belirlenmesi ve bantları istatistiksel bilgilerine göre sıralamak için kullanılan yaygın bir istatistik yöntemidir (Shawky vd., 2019). Optimum bantların belirlenmesinde bantlar arasındaki korelasyon ve varyans istatistikleri kullanılır (Chavez vd., 1982; Pournamdari vd., 2014).

Uydu görüntüsündeki tüm olası 3-bant kombinasyonlarından optimum bant kombinasyonu, en yüksek miktarda 'bilgi' (= standart sapmaların en yüksek toplamı) ve en az tekrarlama miktarı (bant çiftleri arasında en düşük korelasyon) olanıdır (Ren ve Abdelsalam, 2001; Shawky vd., 2019; van der Meer vd., 2012). 3 farklı bant diziliminin farklı kombinasyonlarından üretilen OIF değerleri, uydu görüntüsündeki bantlarından oluşan 3 bandın olası kombinasyonlarının sayısı belirlendikten sonra $(\mathrm{N}=10)$ (1) (ILWIS Yardım Dokümanı) aşağıdaki bağıntı ile hesaplanır (2) (Chavez vd., 1982; Pournamdari vd., 2014).

$$
\begin{gathered}
\left(\begin{array}{c}
\mathrm{N} \\
3
\end{array}\right)=\frac{\mathrm{N} !}{(3 ! *(\mathrm{~N}-3) !)}(1) \\
\mathrm{OIF}=\frac{\mathrm{Std}_{j}+\mathrm{Std}_{j}+\mathrm{Std}_{k}}{\left|\mathrm{Corr}_{j / j}\right|+\left|\mathrm{Corr}_{i, k}\right|+\left|\mathrm{Corr}_{j, k}\right|}
\end{gathered}
$$

N Görüntüdeki kullanılan toplam bant sayısı,

$\operatorname{Std}_{i} \operatorname{Std}_{j} \quad$ Bant i, j ve k 3 farklı bant olmak üzere

$\mathrm{Std}_{k} \quad$ bantlarin standart sapmasi,

Corr $_{i j} \quad$ Bant i, j ve k 3 farklı bant olmak üzere bu

Corr $_{i k} \quad$ farklı bantlar arasındaki korelasyon katsayısı,

Corr $_{j k}$

Sentinel-2 uydu görüntüsüne ait 10 bandın kullanıldığı çalışma alanına ait çerçeve için bantların farklı kombinasyonlarından üretilen OIF değerleri 52North $\mathrm{GmbH}$ firması tarafindan geliştirilen (http://52north.org/ilwis) ILWIS Open ver 3.8.6 yazılımı ile hesaplanmıştır. Sırasıyla i) uydu görüntüsü bantlarının raster veri olarak (Map List) yazılım ortamına aktarılması, ii) bantlara ait varyans-kovaryans matrisi veya korelasyon matrisinin hesaplanmas1, iii) her bir 3 bantl kombinasyonun OIF değerinin hesaplanması ve iv) OIF değerlerinin sıralanması, işlem aşamasıyla her bir bant kombinasyonunun OIF değerleri elde edilmiş ve en yüksek OIF değerine sahip kombinasyonlar belirlenmiştir. 

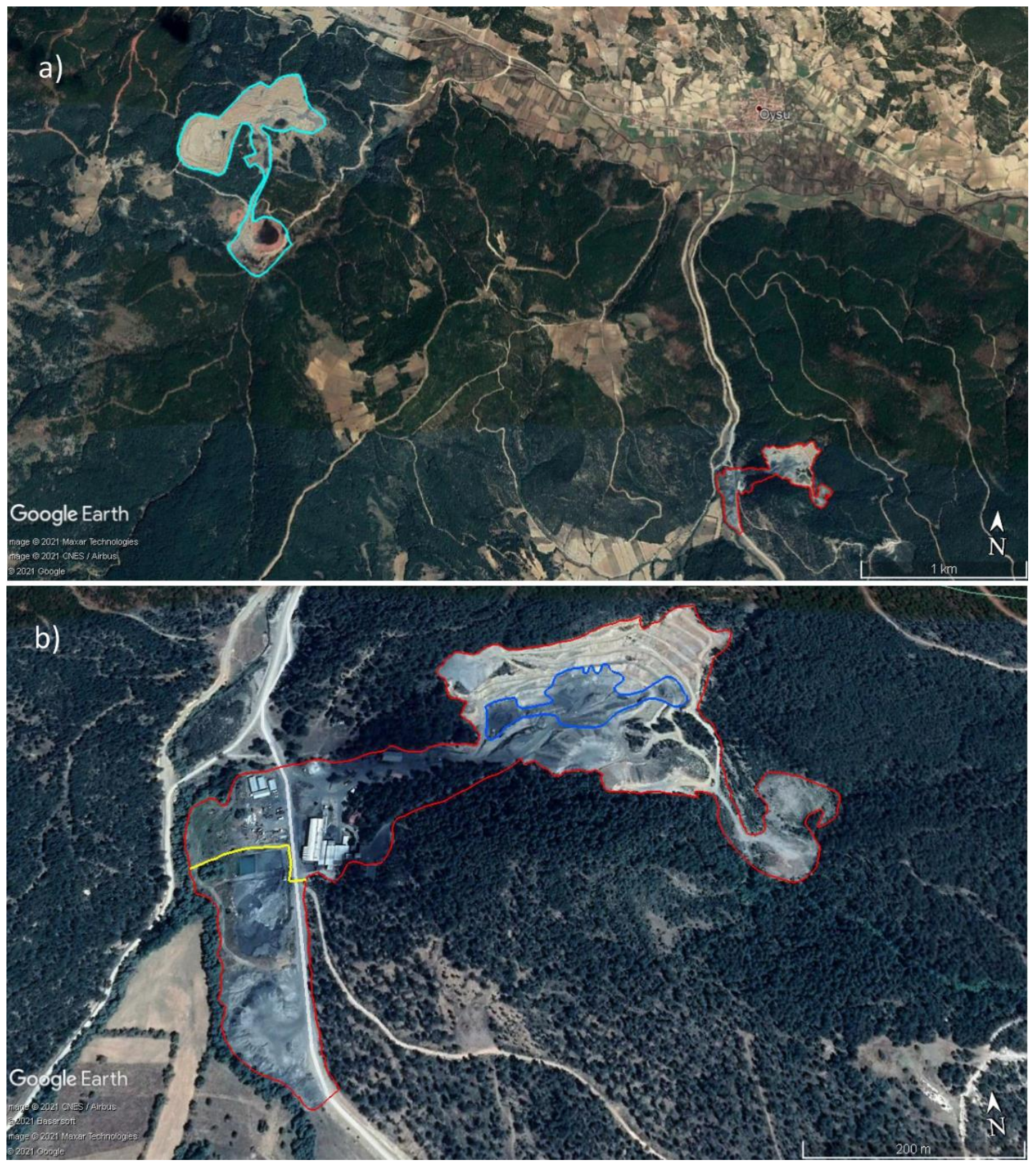

Şekil 3 a)Çalışma alanında kömür madeni (turkuaz renkli alan) ve grafit madeni (kırmızı renkli alan) açık işletmesi b)Grafit Madeni açık işletmesinde açık işletme sınırları (kırmızı renkli alan), cevher zonları (mavi renkli alan), stok sahası (sarı renkli alan)

\section{Araştırma Sonuçları ve Tartışma}

\subsection{Grafit Minerali Spektral Özellikleri}

$\begin{array}{rcccc}\text { Grafit } & \text { minerali } & \text { spektral } & \text { özellikleri, Jet } & \text { Propulsion } \\ \text { Laboratory } & \text { (JPL) } & \text { (Grove } & \text { vd., 1992) } & \text { tarafindan }\end{array}$ (https://speclib.jpl.nasa.gov/documents/jpl_desc) $\quad 0.4-2.5 \quad \mu \mathrm{m}$ aralığında üretilmiş spektral kütüphanelerden derlenmiştir (Şekil 4). Grafit minerali koyu renkli olduğundan diğer minerallere göre spektrumun 0.4-2.5 $\mu \mathrm{m}$ arasındaki yansıtımı oldukça düşüktür. SWIR bölgesindeki yansitım (1610 nm ve $2190 \mathrm{~nm})$ VNIR bölgesindeki yansıtıma göre yüksektir. VNIR bölgesindeki 705 $\mathrm{nm}$ civarındaki Bant 5 'teki yansitım piki ve buna kiyasla bu bölgeye komșu $740 \mathrm{~nm}$ (Bant 6), 783nm (Bant 7) ve 665 nm'deki (Bant 4) emilim karakteristiktir.

\section{2. İstatistiksel Sonuçlar}

ILWIS'te Sentinel-2 raster bantlarından oluşturulan Map List'e ait korelasyon matrisi ve her bir bandın standart sapması elde edilmiştir (Tablo 2). 10 bantlı Sentinel-2 görüntüsünde 3 bant kullanılarak oluşturulabilecek renkli görüntü bant kombinasyonu sayıs1 120'dir. Korelasyon matrisinde $490 \mathrm{~nm}$ (Bant 2) ile $705 \mathrm{~nm}$ (Bant 5) aralığındaki bantların, 783 (Bant 7) nm ile $865 \mathrm{~nm}$ (Bant $8 \mathrm{~A}$ ) aralığındaki bantlarla korelasyonu düşüktür. $740 \mathrm{~nm}$ (Bant 6) ile $865 \mathrm{~nm}$ (Bant 8A) arasındaki bantların da $1610 \mathrm{~nm}$ (Bant 11) ve $2190 \mathrm{~nm}$ (Bant 12) aralı̆̆ındaki bantlarla korelasyonu düşüktür. Bunun tersine $1610 \mathrm{~nm}$ (Bant 11) ve $2190 \mathrm{~nm}$ (Bant 12) aralı̆̆ındaki bantların $490 \mathrm{~nm}$ (Bant 2) ile $705 \mathrm{~nm}$ (Bant 5) aralığındaki bantlarla korelasyonu yüksektir (Tablo 2). 


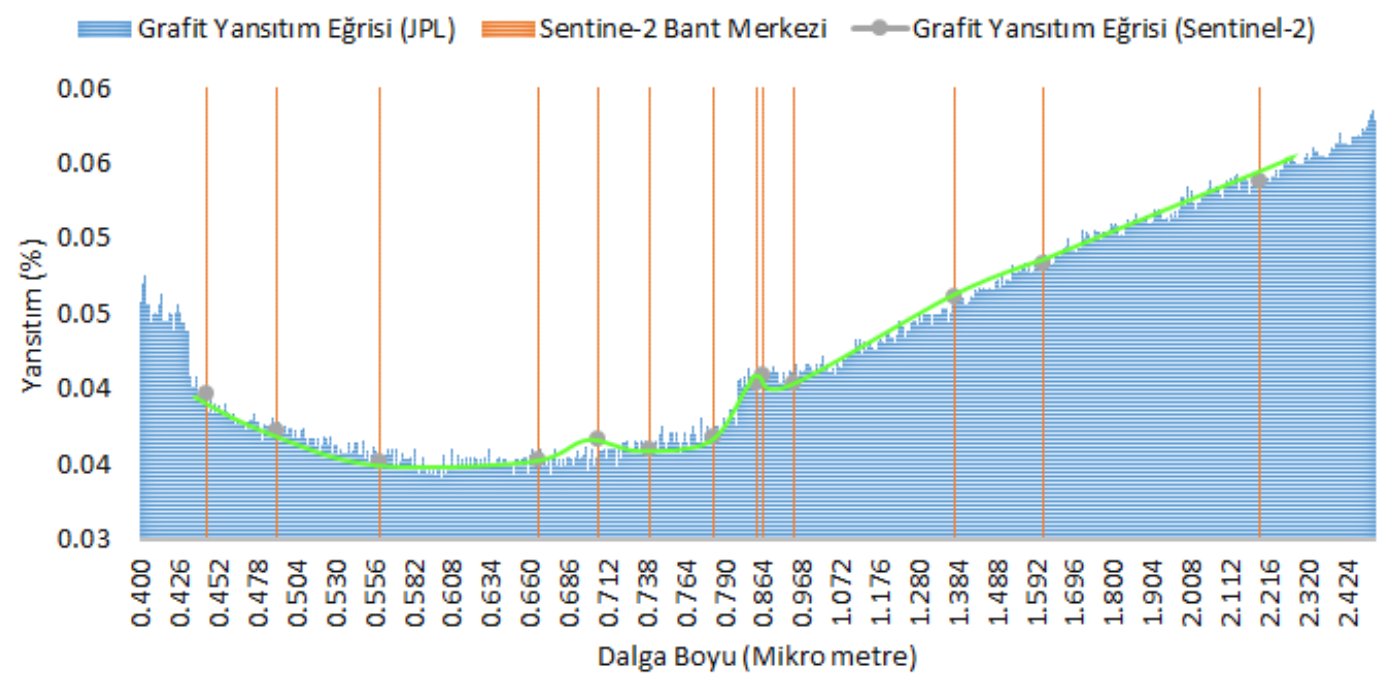

Şekil 4 JPL spektral kütüphanesinde Grafit Minerali spektrumu, Sentinel-2 uydu görüntüsü bant merkezleri, grafit spektrumunun Sentinel-2 bant merkezlerine göre yeniden örneklenmiş versiyonu (yeşil renkli)

Tablo 2 Sentinel-2 uydu görüntülerine ait bantlartn korelasyon matrisi ve her bir bandın standart sapmasl

\begin{tabular}{|c|c|c|c|c|c|c|c|c|c|c|c|}
\hline Korelasyon & Bant 2 & Bant 3 & Bant 4 & Bant5 & Bant 6 & Bant 7 & Bant 8 & Bant 8A & Bant 11 & Bant 12 & Std. Sapma \\
\hline Bant 2 & 1.00 & & & & & & & & & & 454.34 \\
\hline Bant 3 & 0.99 & 1.00 & & & & & & & & & 579.47 \\
\hline Bant 4 & 0.96 & 0.98 & 1.00 & & & & & & & & 866.47 \\
\hline Bant 5 & 0.93 & 0.96 & 0.97 & 1.00 & & & & & & & 827.63 \\
\hline Bant 6 & 0.71 & 0.77 & 0.73 & 0.81 & 1.00 & & & & & & 644.52 \\
\hline Bant 7 & 0.58 & 0.64 & 0.59 & 0.68 & 0.97 & 1.00 & & & & & 687.49 \\
\hline Bant 8 & 0.59 & 0.66 & 0.60 & 0.67 & 0.95 & 0.97 & 1.00 & & & & 742.93 \\
\hline Bant 8A & 0.58 & 0.64 & 0.60 & 0.69 & 0.97 & 0.99 & 0.97 & 1.00 & & & 721.00 \\
\hline Bant 11 & 0.87 & 0.89 & 0.92 & 0.94 & 0.74 & 0.63 & 0.63 & 0.66 & 1.00 & & $1,134.60$ \\
\hline Bant 12 & 0.90 & 0.91 & 0.93 & 0.94 & 0.69 & 0.56 & 0.56 & 0.58 & 0.98 & 1.00 & 989.02 \\
\hline
\end{tabular}

\subsection{OIF Sonuçları}

Tabloda verilen korelasyon matrisi ve standart sapma değerleri kullanılarak hesaplanan her bir 3'lü bant kombinasyonunun OIF değerleri belirlenmiştir (Tablo 3). OIF skorlarına göre en fazla bilgi içeren RGB bant kombinasyonları $665 \mathrm{~nm}$ (Bant 4), $783 \mathrm{~nm}$ (Bant 7) ile $865 \mathrm{~nm}$ (Bant 8A) ve 1610 $\mathrm{nm}$ (Bant 11) ile $2190 \mathrm{~nm}$ (Bant 12) aralıklarının kullanıldı̆̆ 1 kombinasyonlardan oluşmaktadır. En yüksek OIF skoru NIR ve SWIR bantların RGB kombinasyonundan elde edilirken, bunları Red, NIR, SWIR1 bantlarının RGB kombinasyonları izler. Sirasiyla RGB renkli kompozit görüntülerin 8:11:12, 7:11:12, 8A:11:12, 4:8:11, 4:7:11, 4:8A:11 bant kombinasyonlarından oluşan renkli görüntülerde OIF değerleri yüksektir.

\subsection{False Color Composite (FCC) görüntülerde grafit maden alanının ayrımlanması}

OIF skoru sonuçlarına göre en iyi sonuçların elde edildiği farklı bant kombinasyonları için FCC renkli görüntüler üretilmiştir (Şekil 5, Şekil 6).
Tablo 3 her bir 3'lü bant kombinasyonunun OIF değerleri (En yüksek OIF değerine sahip 6 farklı 3 'lü bant kombinasyonu)

\begin{tabular}{lll}
\hline Siralaması & $\begin{array}{l}\text { Sentinel-2B RGB FCC } \\
\text { kombinasyonu }\end{array}$ & OIF Skoru \\
\hline 1. & Bant 8: Bant 11: Bant 12 & 1319.63 \\
2. & Bant 7: Bant 11: Bant 12 & 1297.65 \\
3. & Bant 8A: Bant 11: Bant 12 & 1283.31 \\
4. & Bant 4: Bant 8: Bant 11 & 1270.76 \\
5. & Bant 4: Bant 7: Bant 11 & 1255.47 \\
6. & Bant 4: Bant 8A: Bant 11 & 1247.50 \\
\hline
\end{tabular}

RGB (8:11:12), RGB (7:11:12) ve RGB (8A:11:12) bant kombinasyonlarından üretilen FCC renkli görüntülerde grafit madeni siyah-koyu renkli iken, bölgeye yakın konumda olan kömür madeni stokları gri renkli olarak birbirinden ayrılır. Ancak kömür madeni açık işletmesinde bulunan su havuzlarının ve baraj gölünün grafit madeni ile aynı renge sahip olması nedeni ile ayrımlanamadığı̆ gözlenir (Şekil 5-b, d). Sağlıklı bitkiler kırmızı, hasat edilmiş tarım bitkileri parlak renkleri ile kolayca tanımlanabilir. RGB (8:11:12), RGB (7:11:12) ve RGB (8A:11:12) bant kombinasyonlarından üretilen FCC renkli 
görüntülerde grafit madeni benzer/yakın renge sahip olduğundan sadece RGB (8:11:12) çıktısı verilmiştir (Şekil 5-b, d).

RGB (4:8:11), RGB (4:8A:11) ve RGB (4:7:11) bant kombinasyonlarından üretilen FCC renkli görüntülerde grafit madeni kırmızı renklidir (R:683 G:613 B:878). Grafit madeni bu bant kombinasyolarında bitki, kömür madeni ve çevre litolojilerden kolayca ayrımlanır. Kömür madeni içindeki su havuzları ve baraj gölü siyah renklidir (R:1 G:1 B:1). Su ile grafit madeni, farklı renklere sahip olması nedeni ile bu bant kombinasyonlarında birbirinden kolayca ayrımlanır (Şekil 5-a, c).

İnceleme alanında RGB (4:8:11), RGB (4:8A:11) ve RGB $(4: 7: 11)$ bant kombinasyonlarından üretilen FCC renkli görüntülerde grafit madeni benzer/yakın renge sahip olduğundan sadece RGB (4:7:11) çıktısı verilmiştir (Şekil 5-a, c).

\subsection{Tartışma}

Uzaktan algilama yöntemleri ile doğrudan grafit cevherleşmelerinin belirlenmesi güncel bir konudur. Grafit mineralinin elektromanyetik spektrumun 400-2500 nm arasındaki yansıtımı yok denecek kadar azdır. JPL tarafindan laboratuvar ortamında ölçülmüş spektral özelliklerinde yansıtım değerleri $\% 0.03-\% 0.06$ arasında ölçeklendiğinde SWIR ve VNIR tarafında, emilim farklılıklarının olduğu görülür. 400-2500 nm arasında ölçülen spektrum, Sentinel-2 görüntüsünün spektral özelliklerine göre yeniden örneklendiğinde (bkz. Şekil 4), grafit spektrumundaki emilim ve yansıtım karakteristiği olan bölgelerin algılandığı görülür. Optimum bant kombinasyonlarında RGB (8:11:12) kullanılması, kızılötesi bölgede yansıtımı olmayan/çok düşük olan su yüzeyleri ile grafit cevherleşme zonlarının karışmasına neden olur. OIF yöntemi jeolojik uzaktan algılama uygulamalarında (Gad ve Kusky, 2007; Öztan ve Süzen, 2011; Pournamdari vd., 2014; Zabc1, 2020) yaygın kullanılan bir yöntemdir. Zabcı (2020), litolojik ayrımlamada Sentinel-2 görüntüsüne ait [RGB 8A:10:2] FCC kombinasyonunu, Emam vd., (2018) litolojik ayrımlamada Landsat-OLI için FCC [RGB 6:5:1], Aster için FCC [RGB 9:4:1] kombinasyonunu belirlemiştir.

OIF yöntemi başarılı sonuçlar üretmekle birlikte, özellikle cevherleşmeye ait spektral kütüphanelerin kullanıldığı SAM (Spectral Angle Mapper) gibi eğitimli sınıflandırma yöntemleriyle grafit cevherleşmeleri daha ileriki çalışmalara konu edilmelidir. Laboratuvar ortamında JPL tarafından ölçülen spektral kütüphane için kullanılan örnekler ile çalıșılan cevherleşme alanındaki grafit minerallerinin saflık ve karbon içeriği farklı olabileceğinden, araziden alınmış örneklerin spektral özelliklerinin kullanımının etkileri de bu çalışmalarda incelenmelidir.
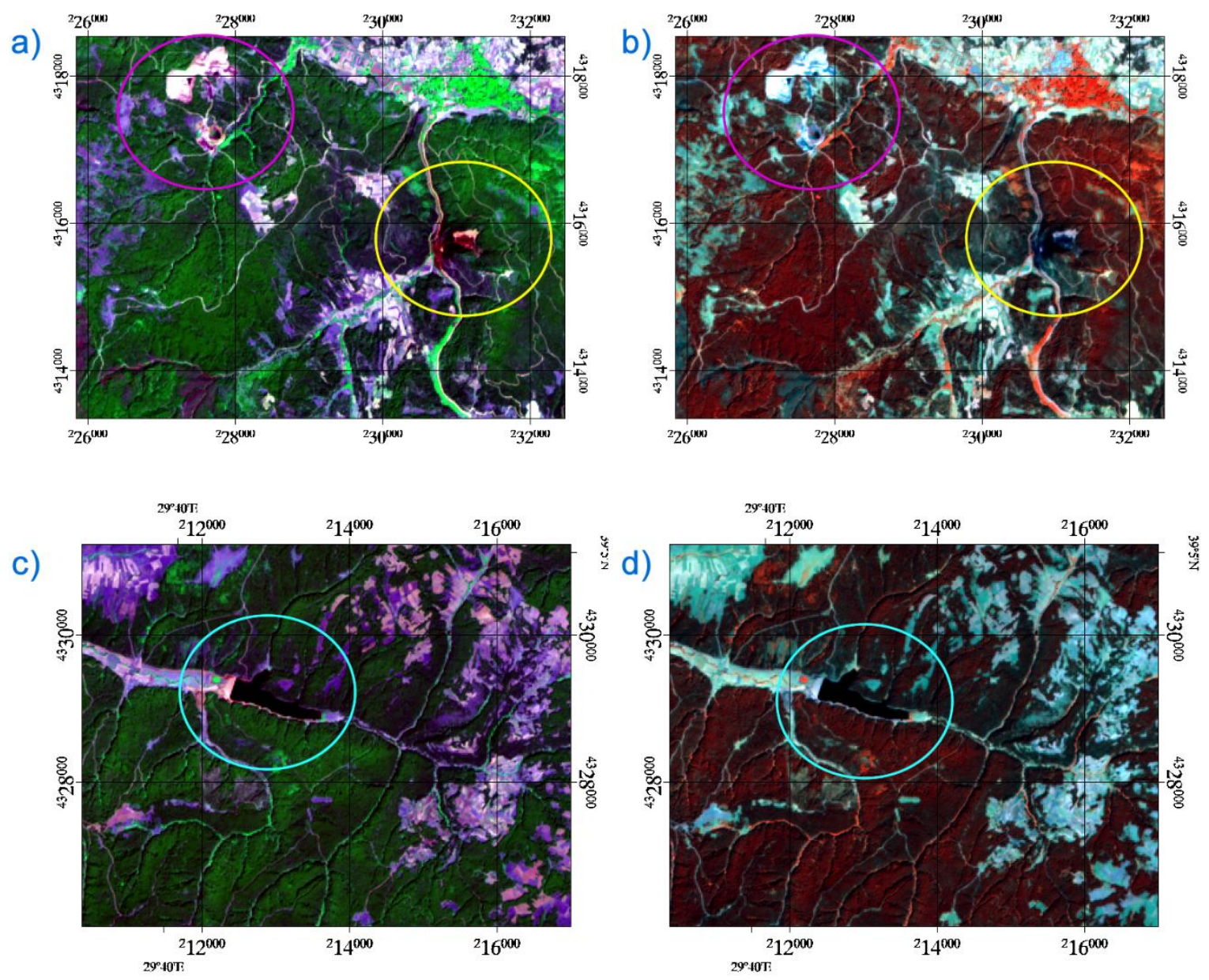

Şekil 5 a)RGB 4:7:11 bant kombinasyonu FCC görüntüsünde grafit maden ocă̆l (Sarl renkli çerçeve), kömür maden ocağı (pembe renkli çerçeve) b)RGB 8:11:12 bant kombinasyonu FCC görüntüsünde grafit maden ocă̆l (Sarı renkli çerçeve), kömür maden ocă̆l (pembe renkli çerçeve) c)RGB 4:7:11 bant kombinasyonu FCC görüntüsünde baraj gölü (turkuaz renkli çerçeve) d)RGB 8:11:12 bant kombinasyonu FCC görüntüsünde baraj gölü (turkuaz renkli çerçeve) 

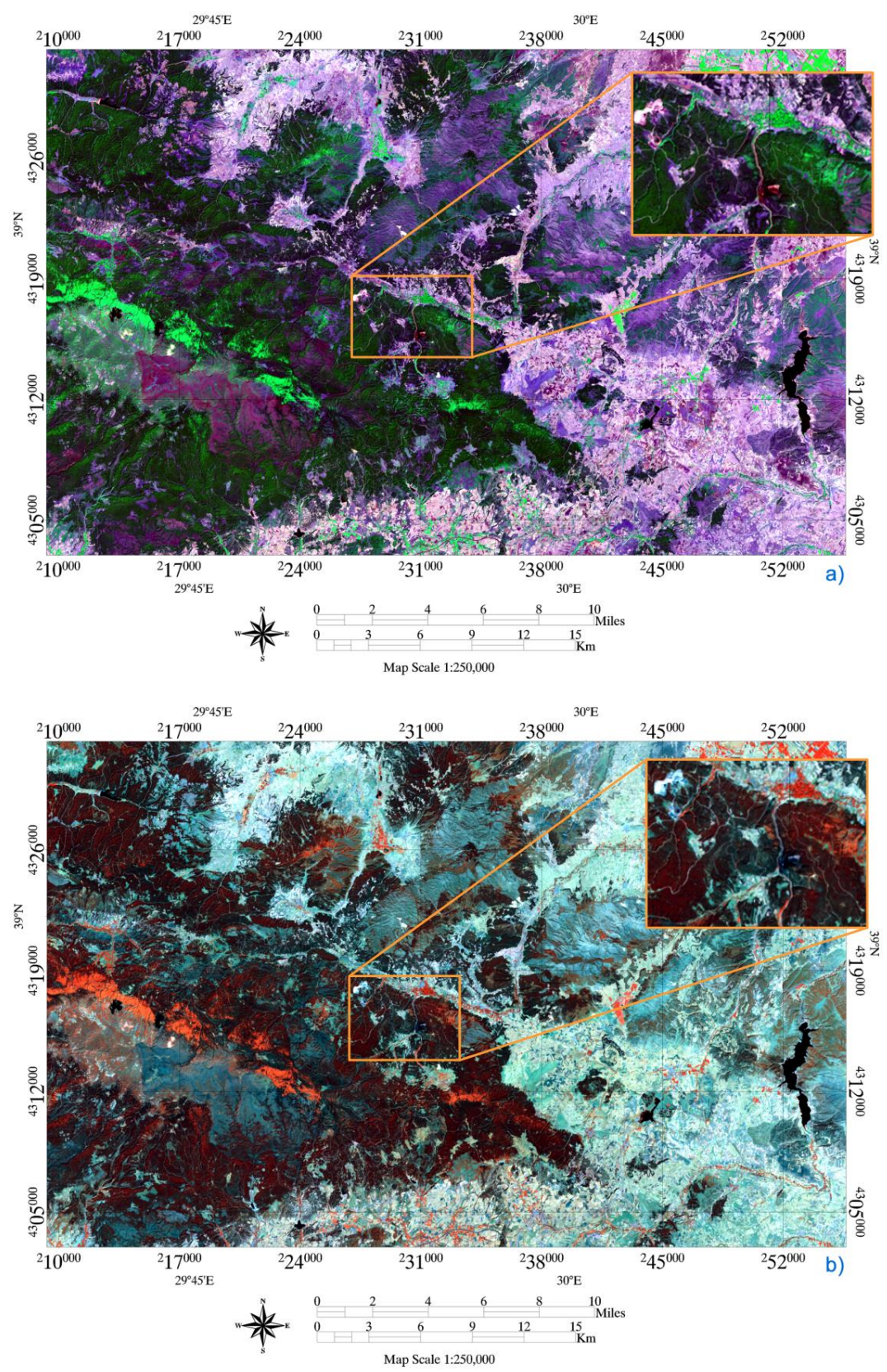

Şekil 6 Çalışma Alanı a) RGB 4:7:11 Bant kombinasyonu FCC görüntüsü, b) RGB 8:11:12 Bant kombinasyonu FCC görüntüsü

\section{Sonuç}

Grafit mineralinin SWIR bölgesindeki yansıtımının, VNIR bölgedeki yansıtıma göre yüksek olması, OIF RGB renk kombinasyonunda Bant 11 ve Bant 12'nin kullanımında maksimum bilginin elde edilmesi olasılığında da ortaya çıkmıştır. Grafit minerali spektrumunda Bant 8 , Bant 5, Band 11 ve Bant 12'deki yansıtımları karakteristiktir. Buna karşın Bant 4, Bant 6 ve Bant 7'deki diğer bantlara göre emilim gerçekleşir. RGB renk kombinasyonunda maksimum bilgiyi ortaya koyan optimum seçenek, emilimin karakteristik olduğu 2 bant ile yansıtımın karakteristik olduğu 1 bant [RGB 4:7:11] ya da yansitım karakteristik olduğu 2 bant ile emilimin karakteristik olduğu 1 bant [RGB 4:8:11] kombinasyonu, grafit mineral cevherleşmelerinin diğer litolojik birimler ve bitki vb. diğer arazi örtüsü bileşenlerinden başarılı bir şekilde ayrımlanmasını ve tanımlanmasını sağlar.
Spektrumun VNIR ve SWIR bölgesinde uzamsal çözünürlüğü 10,20 ve $60 \mathrm{~m}$ arasında değişen 13 bant içeren Sentinel-2 görüntüleri grafit cevherleşmelerinin belirlenmesinde başarılı sonuçlar ortaya koymaktadır. Sentinel-2 uydu görüntüsü spektral özellikleri, grafit minerali yüksek spektral çözünürlüklü spektrumundaki önemli emilim ve yansıma bölgelerinde algılama yapabilen bantlara sahiptir. Çalışmada sunulan yöntemle, Sentinel-2 uydu görüntüleri kullanılarak grafit cevherleşmeleri belirlenebilir.

$\mathrm{Bu}$ çalışmada sunulan yöntemin dışında konu ile ilgili ileri çalışmalarda, Sentinel-2 uydu görüntüsündeki her bir bandın birbiri ile olan bant oranlarından üretilen OIF değerleri ile bant oranları optimum RGB kombinasyonları üretilerek değerlendirmeler yapılabilmesi bu tür araştırmalara önemli katkılar sağlayacaktır. 


\section{Teşekkür}

Yazar, çalışmada kullanılan Sentinel-2 uydu görüntülerinin sağlanması konusundaki desteklerinden dolayı Avrupa Uzay Ajansı'na teşekkür eder.

\section{Kaynakça}

Baran, H. (2021). Hakkâri ili baz metal yataklarının uzaktan algılama ile belirlenmesi. Gümüşhane Üniversitesi Fen Bilimleri Enstitüsü Dergisi, 11 (2) , 339-347. DOI: 10.17714/gumusfenbil.829156

Canbaz, O., Gürsoy, Ö., Gökce, A. (2017). Determination of Hydrothermal Alteration Areas by Aster Satellite Images: Ağmaşat Plato- Zara (Sivas) / Turkey Sample. Cumhuriyet Science Journal, 38 (3) , 419-426. DOI: 10.17776/csj.340473

Cardoso-Fernandes, J., Teodoro, A., Lima, A. 2018. "Potential of Sentinel-2 data in the detection of lithium (Li)-bearing pegmatites: a study case" (C. 10790, s. 47). SPIE-Intl Soc Optical Eng.

Chavez, P., Berlin, G., Sowers, L. 1982. "Statistical Method For Selecting Landsat MSS Ratios". Journal of Applied Photographic Engineering 8(1):23-30.

Ciampalini, A., Garfagnoli, F., Antonielli, B., Moretti, S., Righini, G. 2013. "Remote sensing techniques using Landsat ETM+ applied to the detection of iron ore deposits in Western Africa". Arabian Journal of Geosciences, 6, 4529-4546.

Çuhadaroğlu, A. D., Kara, E. 2018. "Grafit: Bir Genel Değerlendirme". Teknik Bilimler Dergisi, 8(1), 14-33. https://dergipark.org.tr/en/pub/tbed/330629

Demirtaş, M., Turan, A., Car, E., Yücel, O. 2017. "Kritik Hammaddeler". Metalurji ve Malzeme Mühendisleri Odası Dergisi, 183, 28-33.

Emam, A., Hamimi, Z., El-Fakharani, A., Abdel-Rahman, E., Barreiro, J. G., Abo-Soliman, M. Y. 2018. "Utilization of ASTER and OLI data for lithological mapping of NugrusHafafit area, South Eastern Desert of Egypt". Arabian Journal of Geosciences, 11(23), 1-22.

ENTR, D. G. 2014. "Report on critical raw materials for the EU: Report of the Ad hoc Working Group on defining critical raw materials". Ares (2015) (C. 1819503).

ESA. 2013. "SENTINEL-2 User Handbook". Paris.

Gad, S., Kusky, T. 2007. "ASTER spectral ratioing for lithological mapping in the Arabian-Nubian shield, the Neoproterozoic Wadi Kid area, Sinai, Egypt". Gondwana Research, 11(3), 326-335.

Ge, W., Cheng, Q., Jing, L., Wang, F., Zhao, M., Ding, H. 2020. "Assessment of the capability of sentinel-2 imagery for ironbearing minerals mapping: A case study in the cuprite area, nevada". Remote Sensing, 12(18), 3028.

Grove, C. I., Hook, S. J., Paylor, E. D. 1992. "Laboratory reflectance spectra for 160 minerals 0.4-2.5 micrometers: JPL Publication 92-2". Jet Propulsion Laboratory, Pasadena, CA.

Hu, B., Xu, Y., Wan, B., Wu, X., Yi, G. 2018. "Hydrothermally altered mineral mapping using synthetic application of Sentinel-2A MSI, ASTER and Hyperion data in the Duolong area, Tibetan Plateau, China". Ore Geology Reviews, 101, 384-397.
İlhan, A., Sarı, R., Çörtenlioğlu, Y. Y. 2020. "Avrupa İçin Yeni Bir Kaynak: Türkiye Grafit Oluşumları". Madencilik Türkiye Dergisi, 87, 5.

İlhan, A., Sarı, R., Yıldırım, Y. 2020. "Hidden graphite resources in Turkey: a new supply candidate for Europe?". Içinde European Geologist Journal- Mineral raw materials in Europe - Chances and challenges for domestic production.

Jara, A. D., Betemariam, A., Woldetinsae, G., Kim, J. Y. 2019. "Purification, application and current market trend of natural graphite: A review". International Journal of Mining Science and Technology, 29(5), 671-689.

Karabacak, M. 2021. "Mikrokristalin Doğal Grafit - Karabacak Madencilik". Tarihinde 30 Mayıs 2021, adresinden erişildi http://www.karabacakmaden.com.tr/2021/01/17/mikrokristal in-dogal-grafit/

MTA, G. M. 2021. "Grafit". Tarihinde 30 Mayis 2021, adresinden erişildi https://www.mta.gov.tr/v3.0/bilgi-merkezi/grafit

MuellerWilm, U. 2019. "Sen2Cor Configuration and User Manual".

Öztan, N. S., Süzen, M. L. 2011. "Mapping evaporate minerals by ASTER". International Journal of Remote Sensing, 32(6), 1651-1673.

Pournamdari, M., Hashim, M., Pour, A. B. 2014. "Spectral transformation of ASTER and Landsat TM bands for lithological mapping of Soghan ophiolite complex, south Iran". Advances in Space Research, 54(4), 694-709.

Purwadi, I., van der Werff, H. M. A., Lievens, C. 2020. "Targeting rare earth element bearing mine tailings on Bangka Island, Indonesia, with Sentinel-2 MSI". International Journal of Applied Earth Observation and Geoinformation, 88, 102055.

Ren, D., Abdelsalam, M. G. 2001. "Optimum Index Factor (OIF) for Aster data; examples from the Neoproterozoic Allaqi Suture, Egypt". Geological Society of America, 336, 289290.

Shawky, M. M., El-Arafy, R. A., El Zalaky, M. A., Elarif, T. 2019. "Integrated image processing and GIS-based techniques using knowledge-driven approaches to produce potential radioactivity map for the uraniferous granite of Egypt". NRIAG Journal of Astronomy and Geophysics, 8(1), 185197.

Soydan, H., Koz, A., Düzgün, H. Ş. 2021. "Secondary Iron Mineral Detection via Hyperspectral Unmixing Analysis with Sentinel-2 Imagery". International Journal of Applied Earth Observation and Geoinformation, 101, 102343.

Toprak, S. 2017. "Grafit, Ülkemizdeki Grafit Oluşumları ve Sorunları". Içinde Maden Jeologları Derneği Etkinliği (s. 2).

Tufan, B., Batar, T. 2015. "Improvement Of Oysu Graphite Ore Flotation Parameters". Journal of Institute of Science, 19(3), $17-25$.

van der Meer, F. D., van der Werff, H. M. A., van Ruitenbeek, F. J. A., Hecker, C. A., Bakker, W. H., Noomen, M. F., ... Woldai, T. 2012, Şubat 1. "Multi- and hyperspectral geologic remote sensing: A review". International Journal of Applied Earth Observation and Geoinformation. Elsevier B.V.

van der Werff, H., van der Meer, F. 2015. "Sentinel-2 for mapping iron absorption feature parameters". Remote Sensing, 7(10), 12635-12653.

Zabcı, C. 2020. "Çok bantlı Landsat 8-OLI ve Sentinel-2A MSI uydu görüntülerinin karşılaştırmalı jeoloji uygulaması: Örnek çalışma alanı olarak Doğu Anadolu Fayı boyunca Palu Hazar Gölü bölgesi (Elazığ, Türkiye)". Geomatik, 6(3), 238246. 